\title{
Study of Chondrosarcoma in Northwest Region of Libya
}

\author{
Abdullatef Nureddin*1 and Moftah Sherad ${ }^{2}$ \\ ${ }^{1}$ Department of Oral Surgery and oral pathology, Tripoli University, Libya \\ ${ }^{2}$ General Pathology Department, Sabrath Tumor Institute, Libya
}

Received: September 17, 2017; Published: October 03,2017

*Corresponding author: Abdullatef Nureddin, Faculty of Dentistry, Department of Oral Surgery, Oral Medicine and oral pathology, Tripoli University, Libya; Tel: 00218914319554; Email: yaema2000@gmail.com

\begin{abstract}
Chondrosarcoma (CS) is a relatively rare malignant tumor of chondroblasts with pure hyaline cartilage differentiation. The neo-plastic cells do not synthesize osteoid, but areas of calcification, ossification and myxoid change may be seen. A total of 14 cases were obtained from two major hospitals in the northwest region of Libya over a period of 6 years. Clinico-pathological data were evaluated including age and gender. The result showed that (CS) was slightly more common in females than in males, male to female ratio was (1.7: 2) with a peak incidence in the second and third decades of life. It is concluded from this study that CS is generally a slightly more common in females than in males and more frequently affected patients in the second and third decades of life. There is no any previous published article regarding this aspect in the northwest region of Libya. Therefore, this paper may will bring forward data for further study of CS in future in Libya.
\end{abstract}

Keywords: Age; Gender; Libya; CS; Male to Female Ratio

Abbreviations: CS: Chondrosarcoma; IDH1: Isocitrate Dehydrogenase 1; IDH2: Isocitrate Dehydrogenase 2

\section{Introduction}

Chondrosarcoma is a rare malignant tumor of chondroblasts with pure hyaline cartilage differentiation. The neo-plastic cells do not synthesize osteoid, but areas of calcification, ossification and myxoid change may be seen. Chondrosarcoma is the third most frequent primary malignant tumor of bone exceeded only by myeloma and osteosarcoma. It usually occurs in the trunk bones (pelvic girdle, shoulders, ribs) followed by the femur and humerus $[1,2]$. Chondrosarcomas may be divided in two major categories, central chondrosarcoma (primary or conventional), which arise in the medullary canal and then perforate the cortical plate and surface chondrosarcomas which arise on the bone surface and grow into the adjacent soft tissue, known as peripheral Chondrosarcomas either periosteal or juxtacortical Chondrosarcoma. In addition to central and surface Chondrosarcomas, some pathologists further subdivide Chondrosarcoma into primary which occur de novo and secondary Chondrosarcoma that occur in a preexisting lesions, as well as another three variants of Chondrosarcomas that have distinctive histological features, clear cell Chondrosarcoma, mesenchymal Chondrosarcoma and dedifferentiated Chondrosarcoma [3].

Central Chondrosarcoma may be high grade or low grade neoplasm that occurs in the medullary canal, then grow to perforate the cortex and present in the surrounding soft tissue. It has a wide age range but most frequently seen in fourth or fifth decade of life. Although, the majority of tumors occur in the pelvic bones, proximal humerus, femur, and tibia. Approximately $50 \%$ of cases arise in preexisting enchondromas [4-6]. Clinically, the pain is the most initial symptoms, which mostly indicate a growing lesion, although, radio graphically, central Chondrosarcomas usually appear as a poorly defined zone of stippled radio densities usually associated with cortical thickening [6].

Surface Chondrosarcomas, Almost all surface Chondrosarcomas are low-grade, slow-growing neo-plasma that arise on the bone surface and grow into the surrounding soft tissue. Juxtacortical Chondrosarcoma also called periosteal Chondrosarcoma, is a special surface variant [5,7]. Patients are usually between ages 20 and 40 and the neo-plasm present with pain and swelling, although most of the cases seen in the femur and pelvic bones. Radio graphically, the lesion shows lobulated masses of stippled and ring like calcification adjacent to the bone surface often accompanied by radiating bone spicules perpendicular to the bone surface and typical Codman's triangle [7]. In general, the histological features of Chondrosarcomas, whether central or surface, can be grouped in three histologic grades. Grade 1 Chondrosarcoma, is slowgrowing, low-grade malignancy that almost never metastasize. The chondrocytes are present in lacuna and have small, dark nuclei in scanty cytoplasm. Binucleated cells are present but mitotic figures are absent, therefore, distinguishing a grade 1 Chondrosarcoma from enchondroma is extremely difficult. Grade 2 Chondrosarcoma 
is also slow-growing, low-grade malignancy, but more cellular than grade 1 with mild cellular Pleomorphism and few mitotic figures. By contrast, grade 3 Chondrosarcoma is high-grade neoplasm, in which the cytological criteria of malignancy is more obvious and mitotic figures count for 2 per 10 per high power fields [6,8-10].

Clear Cell Chondrosarcoma. Is a rare, low-grade malignant variant of Chondrosarcoma, However, due to radiological and histological features similarities of this neoplasm to chondroblastoma, some pathologisties suggest that clear cell Chondrosarcoma represent a malignant transformation of a preexisting chondroblastoma. The neoplasm tends to occur in older age group and almost always occurs in the epiphyseal end of long bone. Radio graphically, most clear cell Chondrosarcomas, and appear as purely lytic, well-defined epiphyseal lesions that usually lack a sclerotic rim with some areas of calcification. Histologically, clear cell Chonrosarcoma like chondroblastoma contain sheets of rounded cells, arranged in an indistinct lobular pattern with numerous scattered foci of extracellular chon droid matrix [11,12]. Mesenchymal Chondrosarcoma is a rare aggressive malignant variant of Chondrosarcoma characterized by small round blue cells with foci of cartilage differentiation. This neoplasm has a wide age range, but most of the patients are in the second and third decades of life. The neoplasm most frequently involves the bones of the face, ribs, pelvis and femur. Radio graphically; the malignant tumor appears as poorly defined lytic lesion, usually with faint stippled calcifications, while the characteristic histological feature is the presence of sheets of small round cells with scant cytoplasm [1316].

Dedifferentiated Chondrosarcomas present with pain, usually of only a few months duration, while some patients present with pathological fracture, although patients are usually adults and the pelvis is the most common location followed by femur and humerus. Radio graphically, dedifferentiated Chondrosarcoma appears as a poorly defined radiolytic destructive lesion, usually with stippled calcifications, while the adjacent soft tissue mass is best visualized with MRI. Histologically, the most important feature of dedifferentiated Chondrosarcoma is the close association of two different cellular components; one of these consists of cartilage, which is generally well differentiated, while the second component is the feature of osteosarcoma [17-19]. In the jaws, Chondrosarcomas are extremely rare tumor. The anterior part of the maxilla and posterior part of the mandible are the most common sites frequently involved by the neoplasm, although the tumor may arise in the mandibular symphysis, condylar process, coronoid process and alveolar ridge. The neoplasm may cause widening of the periodontal ligament, teeth exfoliation, root resorption, obliteration of the antrum [20]. The aim of this study was to evaluate age and gender of Chondrosarcoma in the northwest region of Libya and to create a base for further studies in future.

\section{Materials and Methods}

This is a retrospective 6 years hospital based study. Only 14 cases of formalin-fixed, paraffin embedded specimens diagnosed as a conventional Chondrosarcomas were found in 2 major hospitals that have a diagnostic histopathological service in the northwest region of Libya. The 14 cases were collected from pathology departments of Sabrata Tumor Institute and Tripoli Central Hospital, between the years 1996 and 2002. The diagnosis of all the cases based on relevant histopathological reports was conventional Chondrosarcoma, while sub variant or grade of the tumour was not written. In order to confirm the diagnosis of all the cases included in these study two slides from each formalin-fixed, paraffin embedded specimens were re-examined by two pathologists from Pathology Department, Faculty of Medicine, Tripoli University. Those that did not fit the characteristic histopathological criteria as described widely in the literature of Chondrosarcomas were excluded from the study.

Traditionally the histopathological features of this tumor shows a hyaline cartilaginous proliferation, with a sarcomatous stroma containing malignant chon droid cells of stellate, spindle-shaped, or rounded cells. Presence of mitotic figures is rare, and their absence does not rule out the diagnosis of Chondrosarcoma. Criteria for diagnosis of malignancy in this tumor include an increased number of cells, increased size of the nuclei, cells with binucleate forms, or giant cell tumor formation. Patients medical records were retrieved from archives of the Pathology Departments of mentioned hospitals and relevant clinic-pathological data including age, gender and location of tumor reviewed and tabulated (Table 1).

Table 1 : Clinic Pathological Data of Chondrosarcomas.

\begin{tabular}{|c|c|c|c|c|}
\hline Cases & Age & Gender & Site & Diagnosis \\
\hline 1 & 12 & F & Finger & Chondrosarcoma \\
\hline 2 & 10 & M & Pelvis & Chondrosarcoma \\
\hline 3 & 25 & F & Femur & Chondrosarcoma \\
\hline 4 & 17 & M & Femur & Chondrosarcoma \\
\hline 5 & 22 & F & Maxilla & Chondrosarcoma \\
\hline 6 & 20 & F & Knee & Chondrosarcoma \\
\hline 7 & 23 & M & Tibia & Chonrosarcoma \\
\hline 8 & 24 & F & Pelvis & Chondrosarcoma \\
\hline 9 & 19 & M & Tibia & Chonrosarcoma \\
\hline 10 & 29 & M & Nose & Chondrosarcoma \\
\hline 11 & 27 & F & Mandible & Chondrosarcoma \\
\hline 12 & 40 & F & Pelvis & Chondrosarcoma \\
\hline 13 & 46 & F & Pelvis & Chondrosarcoma \\
\hline 14 & 18 & M & Clavicle & Chondrosarcoma \\
\hline Reslts & & & & \\
\hline
\end{tabular}

Results

\section{Age Distribution}

The age range was between 10-46 years. Examined by decade of age, 6 out of 14 (43\%) of Chondrosarcoma cases were diagnosed in patients with age range 10-20 years of age ( second decade) and 6 out of 14 cases (43\%) were diagnosed in patients between 21 30 years of age (third decade). The remaining 2 case (14\%) were diagnosed in patient with ages between 31 and 50 years (fourth and fifth decade). The mean age of the patients was 24 years (Table 2). 
Table 2 : Age Distribution of Patients.

\begin{tabular}{|c|c|c|c|c|c|c|c|}
\hline Age & $\mathbf{1 0 - 2 0}$ years & $\mathbf{2 1 - 3 0}$ & $\mathbf{3 1 - 4 0}$ & $\mathbf{4 1 - 5 0}$ & Over 50 years & Mean & Total Number \\
\hline CS Cases & 6 & 6 & 1 & 1 & - & 24 & 14 \\
\hline
\end{tabular}

\section{Gender Distribution}

6 out of 14 Chondrosarcoma cases (43\%) were present in male patients. The remaining 5 cases (57\%) were in female patients (Table 3). When comparing the incidence of cases of males versus females by age. Chondrosarcoma was slightly more common in

Table 3 : Gender Distribution of Patients.

\begin{tabular}{|c|c|c|c|}
\hline Cases & Number of males & Number of females & Total number of cases \\
\hline CS & 6 & 8 & 14 \\
\hline
\end{tabular}

\section{Discussion}

There is no relevant study or available data in the literature about Chondrosarcoma in north western territories of Libya. Therefore, the reported data in this article may constitute the first published study of CS, thus expanding the reliable and representative of Libyan population in northwest region of Libya. 14 cases of Chondrosarcomas were collected from pathology departments of Sabrath Tumour Institute and Tripoli Central Hospital during 1996-2002 to evaluate age and gender distribution of a rare malignant chon droid forming tumour (CS). Chondrosarcoma is a malignant tumour of mesenchymal origin characterized by the formation of cartilaginous matrix by neo-plastic cells. It is very variable in clinical and histopathological features. It can be both primary and secondary. Several subtypes have been described but CS usually presents as conventional type. In order to establish correct subtypes and grading, histological findings should always be correlated to imaging [21,22]. Chondrosarcoma is the third most common primary malignancy of the bone after multiple myeloma and osteosarcoma, it accounts for $20 \%$ of bone primary sarcomas [23]. Radio graphically, the lesion shows lobulated masses of stippled and ring-like calcification adjacent to the bone surface often accompanied by radiating bone spicules perpendicular to the bone surface and typical Codman's triangle [7].

Age distribution: This study showed that age distribution of Chondrosarcoma was between 10-46 years with mean of 24 years. The peak incidence of the lesion was second and third decades of life which accounts for about $86 \%$ of cases while fourth and fifth decades showed only $14 \%$ of cases (Table 2). When comparing data with international reports, the age range was nearly equal to several studies that the neo-plasm has a wide age range, but most of the patients are in the second and third decades of life [14] and [7,23] who reported that Patients are usually between ages 20 and 40 years. In contrast to other studies that showed CS has a high incidence between the fourth and sixth decades of life [23-25], while others described that the majority of patients affected are over 50 years old [2,26]. However, Differences a cross epidemiological studies conducted in different parts of the world in incidence and frequency of age by decade of patients affected by CS may somewhat reflect or a representative of genetic background or a largely unknown risk factors. On the other hand, possible risk females than in males. The male to female ratio was (1.7: 2). Data from this study also showed that Chondrosarcoma was more frequently seen in patients of second and third decades of life which accounts for about $86 \%$ of cases in contrast to fourth decade that showed only $14 \%$ of cases and no cases were seen over 50 years of life.

factors include therapeutic radiation for cancers and occupational exposures to carcinogenic substances.

Investigators have hypothesized that the tumor may originate from chondrocytes, emberyonal chondroid, or pluripotential mesenchymal stem cells. Interestingly, there is an increased risk for Chondrosarcoma among patients with Ollier disease and Maffucci syndrome. These forms of chondromatosis are associated with somatic mutation in Isocitrate Dehydrogenase 1 (IDH1) gene and isocitrate dehydrogenase 2 (IDH2) gene [27]. Furthermore, the main symptom of CS is progressive swelling, generally associated with pain [24]. Many patients have symptoms for several years before being visited by a surgeon. Because of the relative indolence and frequent misdiagnosis of these tumours, Gohla et al. [25] and Lee et al. [26] reported that the length of time between the first symptoms and the first surgery ranged from 2 months to 30 years. Thus, these data reported may explain in some series of increasing incidence of Chondrosarcoma in middle age group.

\section{Gender Distribution}

This study showed that CS is slightly more common in females than males. The female to male ratio was 2: 1.7). 6 out of 14 Chondrosarcoma cases (43\%) were present in male patients. The remaining 8 cases (57\%) were in female patients (Table 3). This result is consistent to some studies [28], but other series reported that CS has a slight male predilection [26]. These distinctive results may reflect regional factors, environmental factors, size of study and subtype or variant of Chondrosarcoma.

\section{Conclusion} northwest region of Libya was more common in the second and third decades of life and it is slightly more common in females than males.

\section{Acknowledgment}

We would like to acknowledge the help of pathology departments of Sabratha Tumour Institute and Tripoli Central Hospital, Tripoli, Libya.

\section{References}

1. Sanerkin NG (1980) Definitions of osteosarcoma, chondrosarcoma, and fibrosarcoma of bone. Cancer 46(1): 178-185.
It is concluded that the incidence of Chondrosarcoma in 
2. Bartalena T, Rimondi E, Rossi G, Bianchi G, Alberghini M (2007) Low grade central chondrosarcoma of the fifth costotransverse joint. Australas Radiol 51(s1): B122-B125.

3. Murphey MD (2007) World Health Organization classification of bone and soft tissue tumors: modifications and implications for radiologists. Semin Musculoskelet Radiol 11(3): 201-214.

4. Mirra JM, Gold R, Downs J, Eckardt JJ (1985) A new histologic approach to the differentiation of enchondroma and chondrosarcoma of the bones. A clinicopathologic analysis of 51 cases. Clin Orthop Relat Res (201): 214-237.

5. Zenmyo M, Komiya S, Nakashima M, Irie K, Kakizoe M, et al. (2000) Giant juxtacortical chondrosarcoma of the humerus. Orthopedics 23(5): 497498.

6. Björnsson J, McLeod RA, Unni KK, Ilstrup DM, Pritchard DJ (1998) Primary chondrosarcoma of long bones and limb girdles. Cancer 83(10): 2105-2119.

7. Schajowicz F (1977) Juxtacortical chondrosarcoma. J Bone Joint Surg Br 59-B(4): 473-480.

8. Coughlan B, Feliz A, Ishida T, Czerniak B, Dorfman HD (1995) p53 expression and DNA ploidy of cartilage lesions. Hum Pathol 26(6): 620624.

9. Kreicbergs A, Slezak E, Söderberg G (1981) The prognostic significance of different histomorphologic features in chondrosarcoma. Virchows Arch A Pathol Anat Histol 390(1): 1-10.

10. Pritchard DJ, Lunke RJ, Taylor WF, Dahlin DC, Medley BE (1980) Chondrosarcoma: a clinicopathologic and statistical analysis. Cancer 45(1): 149-157.

11. Bjornsson J, Unni KK, Dahlin DC, Beabout JW, Sim FH (1984) Clear cell chondrosarcoma of bone. Observations in 47 cases. Am J Surg Pathol 8(3): 223-230.

12. Present D, Bacchini P, Pignatti G, Picci P, Bertoni F et al. (1991) Clear cell chondrosarcoma of bone. A report of 8 cases. Skeletal Radiol 20(3): 187-191.

13. Aigner T, Loos S, Müller S, Sandell LJ, Unni KK et al. (2000) Cell differentiation and matrix gene expression in mesenchymal chondrosarcomas. Am J Pathol 156(4): 1327-1335.

14. Cai L, Gao ZF, Huang XY (2006) [Clinicopathology analysis of mesenchymal chondrosarcoma in soft tissue]. Beijing Da Xue Xue Bao 38(5): 501-505.

15. Granter SR, Renshaw AA, Fletcher CD, Bhan AK, Rosenberg AE (1996) CD99 reactivity in mesenchymal chondrosarcoma. Hum Pathol 27(12): 1273-1276.
16. Nakashima Y, Unni KK, Shives TC, Swee RG, Dahlin DC (1986) Mesenchymal chondrosarcoma of bone and soft tissue. A review of 111 cases. Cancer 57(12): 2444-2453.

17. Puri A, Shah M, Agarwal MG, Jambhekar NA, Basappa P (2009) Chondrosarcoma of bone: does the size of the tumor, the presence of a pathologic fracture, or prior intervention have an impact on local control and survival? J Cancer Res Ther 5(1): 14-19.

18. Rozeman LB, de Bruijn IHB, Bacchini P, Staals EL, Bertoni F, et al. (2009). Dedifferentiated peripheral chondrosarcomas: regulation of EXTdownstream molecules and differentiation-related genes. Mod Pathol 22(11): 1489-1498.

19. Frassica FJ, Unni KK, Beabout JW, Sim FH (1986) Dedifferentiated chondrosarcoma. A report of the clinicopathological features and treatment of seventy-eight cases. J Bone Joint Surg Am 68(8): 11971205.

20. Garrington GE, Collett WK (1988) Chondrosarcoma. II. Chondrosarcoma of the jaws: analysis of 37 cases. J Oral Pathol 17(1): 12-20.

21. Bertoni F, Bacchini P, Hogendoorn PCW (2002) Chondrosarcoma. In: Fletcher, CDM, Unni KK and Mertens F, Eds., World Health Organisation Classification of Tumours. Pathology and Genetics of Tumours of Soft Tissue and Bone. IARC Press, Lyon, pp. 247-251.

22. Miyawaki T, Kinoshita Y, Lizuka T (1997) A Case of Ollier's Disease of the Hand. Annals of Plastic Surgery 38(1): 77-80.

23. Aprin H, Riseborough EJ, Hall JE (1982) Chondrosarcoma in Children and Adolescents. Clinical Orthopaedics and Related Research, 166: 226232.

24. Roberts PH, Price CH (1977) Chondrosarcoma of the Bones of the Hand. Journal of Bone \& Joint Surgery 59: 213-221.

25. Gohla T, Van Schoonhoven J, Prommersberger KJ, Lanz U (2004) Chondrosarcomas of the Hand. Handchir Mikrochir Plast Chir 36: 328332.

26. Lee SY, Lim YC, Song MH, Seok JY, Lee WS, et al. (2005) Chondrosarcoma of the head and neck. Yonsei Med J 46(2): 228-232.

27. Neville BM, Damm D, Allen C, Bouqout J (2009) Text book of oral and maxillofacial pathology. 2nd ed. Chapter 14 (bone pathology), WB Saunders co, USA, pp. 618.

28. Shmookler B, Bickels J, Jelinek J, Sugarbaker P, Malawer M (2001) Bone and Soft-Tissue Sarcomas: Epidemiology, Radiology, Pathology and Fundamentals of Surgical Treatment. Musculoskeletal Cancer Surgery, Springer, Netherlands, p. 3-35.

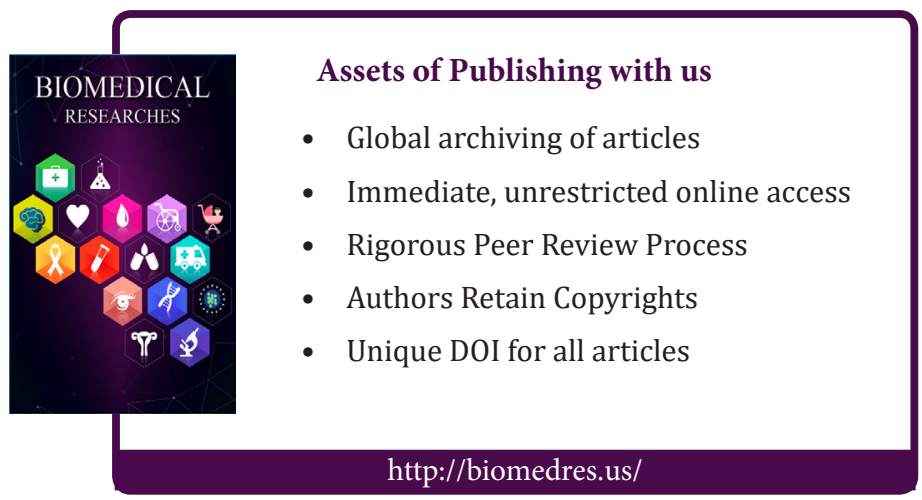

